Bull. Mater. Sci., Vol. 5, No.2, June 1983, pp. 97-101. (C) Printed in India.

\title{
Toxicity screening of candidate materials for the fabrication of a bubble oxygenator : A preliminary report
}

\author{
P V VEDANARAYANAN, K RATHINAM and \\ A C FERNANDEZ \\ Division of Material Toxicology, Sree Chitra Tirunal Institute for Medical Sciences and \\ Technology, Biomedical Technology Wing, Poojapura, Trivandrum 695 012, India
}

MS received 31 December 1981

\begin{abstract}
The hazards encountered in the clinical use of medical devices and implants have been referred in this paper to emphasise the need for and relevance of carrying out appropriate toxicological investigations before such items are manufactured and marketed. Different formulations of polyvinyl chloride, low density polyethylene, high density polyethylene and polyester fabric were subjected to various tests to determine their biocompatibility/safety for their eventual use as components in a bubble oxygenator. The test methods together with the results obtained are described and discussed.
\end{abstract}

Keywords. Disposable bubble oxygenator; polyvinyl chloride; safety evaluation; acute systemic toxicity test; haemolysis test; tissue irritation.

\section{Introduction}

A variety of man-made materials are being employed in the fabrication of disposable devices and permanent implants in medicine and surgery. Collectively known as "medical devices" they comprise some 20,000 different items ranging from a simple disposable thermometer to a sophisticated prosthetic heart valve. These diverse items are made up of heterogenous materials such as plastics, metals, alloys, fabrics, ceramics etc. The final selection of materials is made to suit the particular end use of the device (Williams and Roaf 1973). Introduction of a man-made material/ foreign material into the body environment can give rise to harmful effects (Autian 1967, 1975a). The problems encountered are manyfold and are enumerated below to emphasise the need for the development of adequate testing protocols in order to ensure the safety of materials before the final fabrication of a device is attempted.

A medical device while in contact with the human body can give rise to a variety of problems such as systemic toxicity, thrombus formation, haemolysis, tumor formation, allergic response etc. (Fischer 1967; Bischoff and Bryson 1964). Toxic hazards can also develop due to any treatment applied to the final device, like sterilization (Hiros et al 1963; O'leary and Guess 1968; Roberts and Baker 1969; McGunnigle et al 1975). For example, ethylene oxide used in the sterilization of plastic devices if not desorbed properly can react with the adjacent tissue and produce irritation and also that if a material has chlorides present in it, ethylene oxide can react with it to produce ethylene chlorohydrin, a very toxic agent. The biological environment may also exert significant changes in the implanted materials which 
are generally considered to be stable. Embolism in coronary arteries has been reported as a result of degradation of a prosthesis, part of which has been made up of teflon (Aquino and Skinysness 1963). Occurrence of phthalic acid esters in various commercially available sodium chloride injection IP stored in PVC containers has recently been reported (Rathinam et al 1981). It has been demonstrated that the anticoagulants contained in PVC blood bags can extract one of the plasticizers from it (Guess et al 1967). Plasticizers have been recovered from tissues, urine and blood of patients who had received transfusions of blood stored in PVC bags (Jaegar and Rubin 1970). The potency of drug solution stored in PVC bags may be reduced by permeation of the drug into the wall of the container (Autian 1966). Likewise an antibacterial agent can get sorbed into the walls of a container resulting in inadequate levels of the agent to be present in the drug solution which may permit the growth of micro-organisms in the product.

\section{Experimental}

\subsection{Materials and methods}

Six different formulations of polyvinyl chloride (PVC), low density polyethylene, high density polyethylene and polyester fabric which were intended to go into the fabrication of a disposable bubble oxygenator (figure 1) were subjected to safety evaluation procedures which comprised of acute systemic toxicity test, intracutaneous irritation test and haemolysis test. Except five different polyvinylchlorides formulated, synthesised and supplied by the Vikram Sarabhai Space Centre, Trivandrum, all other samples were procured from commercial sources.

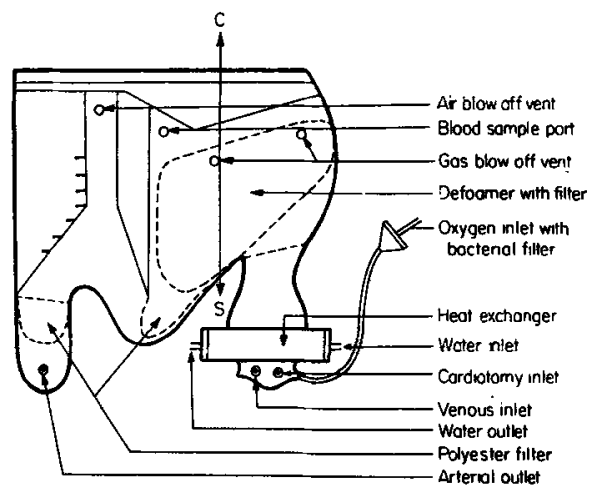

(a)

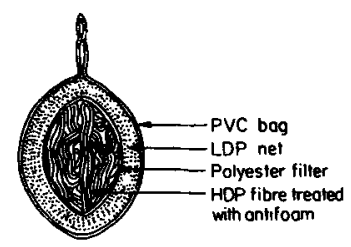

(b)

Figure 1 a-b. a. Schematic drawing of a bubble oxygenator. b. Cross section of the above through the region "C-S". 
Acute systemic injection test in mice is employed to study the toxicity potential of an extract of the material in $0.9 \%$ sodium chloride injection (IP) and refined cotton seed oil by single injection, intravenously/intraperitoneally. Intracutaneous test in rabbit is to assess the tissue irritation capacity of the extracts of the test material in $0.9 \%$ sodium chloride injection (IP) and cotton seed oil. Haemolysis test is carried out to study whether these materials eluate substances causing lysis of human red blood cells.

\subsection{Acute systemic injection test}

Extract of the test material was prepared as follows. The quantity of the material to be extracted was based on the surface area. The surface area used was equivalent to $120 \mathrm{~cm}^{2}$ when the thickness was less than $0.5 \mathrm{~mm}$ and $60 \mathrm{~cm}^{2}$ when the thickness was $0.5 \mathrm{~mm}$ or more. The required quantity of the material was cut into strips of approximately $0.3 \mathrm{~cm}$ in width and $5 \mathrm{~cm}$ in length. Sodium chloride injection (IP $09 \% \mathrm{w} / \mathrm{v}$ ) and cotton seed oil (refined) were used as extraction media.

Each test material was taken in the recommended quantity and made into strips as described above. They were put into $50 \mathrm{ml}$ stoppered test tubes and $20 \mathrm{ml}$ of the extraction medium was added to the test tube. Each sample was prepared in duplicate. A similar test tube with extracting medium alone served as the control. These tubes were placed in an oven for $24 \mathrm{hrs}$ at $70^{\circ} \mathrm{C}$. At the end of the extraction period the tubes were taken out and cooled to room temperature (but not below $22^{\circ} \mathrm{C}$ ) and the tubes were agitated vigorously. The extracts prepared thus were used for the test within a few hrs after extraction.

Albino mice of either sex weighing between 17 and $30 \mathrm{~g}$ were used for this test. Two groups of five mice each were injected intravenously/intraperitoneally $(50 \mathrm{ml} / \mathrm{kg})$ with the extract from each of the two tubes of the same sample. Thus a total of 10 mice received the injection of each type of extract. Ten mice were also injected with control portion of each type of extract. Therefore, a total of 20 mice were used for testing a single material in one extracting medium. The animals were observed, immediately and thereafter for $72 \mathrm{hrs}$ after injection at intervals of 24 and $48 \mathrm{hrs}$. If during the observation period none of the animals treated with the test extract shows a significantly greater reaction than the animals treated with the control extract the test sample meets the requirements of the test. On the other hand, if some of the animals showed signs of toxicity the test was repeated to confirm the same.

\subsection{Intracutaneous irritation test}

Extracts of the test material were prepared as described for the systemic injection test. Albino rabbits of either sex weighing 1.5 to $2 \mathrm{~kg}$ were selected for the test. The fur on the back of the rabbit on both sides of the spinal column over a sufficiently larger area was clipped or reclipped on the day of the test. One rabbit received 10 intracutaneous injections of $0.2 \mathrm{ml}$ extract from one tube on one side and 10 similar injections on the contralateral side using the control saline extract. A second rabbit was similarly treated with the test and control portion of the extracting medium. Thus a total of two rabbits received intracutaneous injections for a single material in one extracting medium. The injection sites were observed at 24,48 and $72 \mathrm{hr}$ 
after injection for gross evidence of tissue reaction such as erythema, oedema and necrosis. The sample meets the requirements of the test if the response of the sample is not significantly greater than that of the control.

\subsection{Haemolysis test}

Though the recommended quantity of the test material is $25 \mathrm{~g}$ it could not be strictly adhered to because of the bulky nature of the material and consequent limitations to contain the amount in a specified volume. In all cases with the exception of polyester cloth the weight chosen was $12 \mathrm{~g}$ and in the case of polyester cloth it was much less. Test samples were taken in $50 \mathrm{ml}$ stoppered test tubes and each sample were used in triplicate. Phosphate buffered saline $(25 \mathrm{ml}$ of $0.85 \%, \mathrm{pH} \mathrm{7.4)}$ with $0.4 \mathrm{ml}$ of ACD preserved fresh human blood was added to the above test tubes. ACD blood $(0.4 \mathrm{ml})$ with $25 \mathrm{ml}$ of $0.1 \% \mathrm{Na}_{2} \mathrm{CO}_{3}$ solution served as positive control ( $100 \%$ haemolysis) while $0.4 \mathrm{ml}$ of ACD blood in $25 \mathrm{ml}$ of phosphate buffered saline ( $\mathrm{pH} 7.4$ ) alone served as negative control $(0 \%$ haemolysis). The tubes were incubated at $35^{\circ} \mathrm{C}$ for $1 \mathrm{hr}$ in an incubator. At the end of the incubation period the supernatant was decanted and centrifuged at $2000 \mathrm{rpm}$ for $3 \mathrm{~min}$. Light transmission (OD) of supernatant liquids were read at $540 \mathrm{~nm}$ in a colorimeter. The percent of haemolysis was calculated by using the formula.

$$
\frac{\text { OD of test material }- \text { OD of negative control }}{\text { OD of positive control }} \times 100
$$

\section{Results and Discussion}

Mice subjected to the systemic injection test with the extracts of the test materials, showed no signs or symptoms suggestive of systemic toxicity up to 7 days. They were alert, active and normal in their habits and feeding. There was no change in the behaviour or loss of body weight of these animals from those of the control group which received either, sodium chloride injection IP or refined cotton seed oil, the media of extraction.

The intracutaneous test carried out with the extracts of sodium chloride injection IP and refined cotton seed oil did not elicit significant erythema, oedema or necrosis suggestive of cutaneous irritation. The scores obtained for the test samples were well comparable to those of controls.

The haemolysis test was carried out using ACD preserved fresh human blood. The results obtained ranged from $0.0 \%$ to $3.8 \%$. Haemolytic values ranging from 0 to $5 \%$ are considered to be well within the permissible limits of haemolysis (Autian 1975b).

The results summarized in table 1 indicate that the candidate materials are devoid of gross toxicity and show promise for further consideration and fabrication of the bubble oxygenator after suitable and actual clinical device testing. 
Table 1. Summary of the results obtained.

\begin{tabular}{lc}
\hline Materials tested & Haemolysis test \\
\hline & \\
PVC-VSSC-1 & 2 \\
PVC-VSSC-2 & 2 \\
PVG-VSSC-3 & 2 \\
PVC-VSSC-4 & 2 \\
PVC-VSSC-5 & 2 \\
PVC-COM-1 & 0 \\
LDP-COM-1 & 0 \\
HDP-COM-1 & 0 \\
Polyester-1 & 3.8 \\
\hline
\end{tabular}

(a) No toxic manifestations were observed in any of the materials tested for acute systemic injection test done at 24,48 and $72 \mathrm{hr}$.

(b) Also no erythema, oedema or necrosis were observed in any of the materials for intracutaneous irritation test done at 24,48 and $72 \mathrm{hr}$.

\section{Acknowledgement}

We sincerely thank Dr M S Valiathan, for necessary facilities.

\section{References}

Autian J $19136 \mathrm{~J}$. Mond. Pharm. 4316

Autian J $1967 \mathrm{~J}$. Biomed. Mater. Res. 1433

Autian J 1975a Essays in toxicology (San Francisco: Academic Press Inc.)

Autian J 1975b Polymers in Medicine and Surgery (New York: Plenum Press) 181

Aquino T T and Skinysness O 1963 Arch. Pathol. 80625

Bischoff F and Bryson G 1964 Progr. Exp. Tumor Res. 585

Fisher A A 1967 Contact dermatitis (Philadelphia: Wea and Febiger).

Guess W L, Jacob J and Autian J 1967 Drug Intelligence 1120

Hirose T, Goldstein R and Bailey C $1963 \mathrm{~J}$. Thorac. Cardiovsc. Surg. 45245

Jaeger R J and Rubin R J 1970 Science 170460

O' Leary R K and Guess W L 1968 J. Pharm. Sa. 5712

McGunnigle R G, Renner J A, Romano S J and Abodeely R A 1975 J. Biomed. Mater. Res. 9273

Rathinam K, Fernandez A C, Vedanarayanan P V, Bhujle V V and Srinivasan K 1981 2nd Annual Meeting of Society of Toxicology India - Abstracts 30

Roberts R E and Rendell-Baker L 1969 Med. Surg. Rec. Fourth Quart. 10

Williams D F and Roaf R 1973 Implants in Surgery (London: W B Saunders Company Ltd.) 